This is an author produced version of a paper published in Forest Ecology and Management. This paper has been peer-reviewed and is proof-corrected, but does not include the journal pagination

Citation for the published paper:

Björklund, N., Lindgren, B. S., Shore, T. L., Cudmore, T. (2009) Can predicted mountain pine beetle net production be used to improve stand prioritization for management?. Forest Ecology and Management.

Volume: 257 Number: 1, pp 233-237

http://dx.doi.org/10.1016/j.foreco.2008.08.034

Access to the published version may require journal subscription. Published with permission from: Elsevier

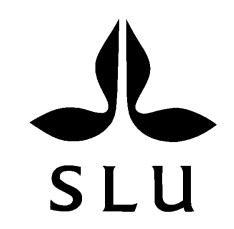

Epsilon Open Archive http://epsilon.slu.se 
1 Forest Ecology and Management 257 (2009) 233-237

2 doi:10.1016/j.foreco.2008.08.034

\section{Can predicted mountain pine beetle net production be used to improve stand prioritization for management?}

Niklas Björklund ${ }^{1}$, B. Staffan Lindgren ${ }^{1}$, Terry L. Shore ${ }^{2}$ and Tim Cudmore ${ }^{1}$
${ }^{1}$ Ecosystem Science and Management, University of Northern British Columbia, Prince George, BC V2N 4Z9, Canada.

${ }^{2}$ Natural Resources Canada, Canadian Forest Service, 506 West Burnside Road, Victoria BC V8Z1M5, Canada.

Corresponding author: Niklas Björklund, present address: Dept. of Ecology, Swedish University of Agricultural Sciences, P.O. Box 7044, S-750 07 Uppsala, Sweden. E-mail: Niklas.Bjorklund@ekol.slu.se, Phone: +46 18672879 


\section{Abstract}

2 Stand-level planning of lodgepole pine management can benefit from the use of mountain

3 pine beetle susceptibility-risk model analyses to assign treatment priority. Priority is

4 currently assigned based solely on relative levels of expected volume loss in the event of

5 a mountain pine beetle outbreak. We evaluated the possibility to predict the relative

6 contribution of brood beetles, by infested stands, to the next beetle generation. Existing

7 data were used to develop generalized parameters for inclusion in predictive models of

8 stand-level mortality and brood production. Model output for independent stands

9 achieved a highly significant relationship with measured outcomes of brood productivity,

10 indicating that relative levels of brood production can be predicted and incorporated into

11 decision-models.

12

13 Keywords: Stand susceptibility index, susceptibility rating, mountain pine beetle, brood

14 productivity, stand-level mortality, net brood production, Dendroctonus ponderosae,

15 Pinus contorta var. latifolia

16 


\section{1. Introduction}

Outbreaks of the mountain pine beetle, Dendroctonus ponderosae Hopk.,

3 can have devastating effects on lodgepole pine, Pinus contorta Dougl., forests in western

4 North America (Amman and Cole, 1983). To minimize negative economic impacts of

5 such outbreaks, it is often necessary to prioritize forest stands for treatment, e.g., clear-

6 cutting and thinning. Prioritization is usually assigned to stands based on a stand

7 susceptibility rating model, which provides a measure of potential losses in the event of a

8 mountain pine beetle invasion. In Canada, the most frequently used model was developed

9 by Shore and Safranyik (1992) and Shore et al. (2000). This model assigns a stand

10 susceptibility value, which reflects the potential percent of basal area lost to bark beetles.

11 Basal area is the total cross-sectional area of trees, measured at breast height (1.4 m), per

12 area unit, and it is used to calculate volume, and hence the economic value of a stand. A

13 measure of the percentage of basal area killed is, therefore, a primary concern for forest

14 managers. However, infested stands also provide the host material for the next generation

15 of beetles and thereby constitute a risk for neighboring stands. There is large variation

16 among stands in terms of the number of brood beetles that are produced, which may be

17 due to differences in tree diameter distribution, attack densities, etc. (Safranyik et al.,

18 1975; Safranyik, 1988). It would, therefore, be valuable if stand-level assessments of the

19 relative contribution by infested stands to the next beetle generation could be used

20 together with the stand susceptibility rating system to aid in stand prioritization.

On average, large trees produce more brood beetles than small trees

23 (Safranyik et al., 1975; Safranyik, 1988), but there is also vast variation in brood 
1 production between similarly sized trees growing in different stands (Safranyik and

2 Carroll, 2006). Such differences may be due to variation among stands with regard to

3 temperature, moisture, intraspecific competition, host quality, host defenses, natural

4 enemies, etc. Thus, the only way to obtain a precise estimate of the net brood production

5 of any given stand is to do field sampling. Appropriate sampling techniques have been

6 developed for sampling mountain pine beetles in lodgepole pine (Safranyik, 1968). To

7 use net brood production within a stand as a tool for stand prioritization, however, it must

8 be possible to generate a brood production estimate before any beetle attack occurs. In

9 this study, we evaluated the possibility of using general mountain pine beetle-lodgepole

10 pine parameters to estimate stand-level net brood production.

\section{2. Materials and methods}

12 We calculated "general" mountain pine beetle-lodgepole pine parameters

13 based on data from an independent large-scale study by Shore et al. (2000). In addition,

14 we intensively sampled 26 stands at the end of mountain pine beetle infestations, i.e.,

15 when most or all susceptible trees had been attacked and killed, for stand specific attack

16 and emergence densities. To evaluate the accuracy of estimates of stand-level net brood

17 production based on "general" parameters generated from Shore et al. (2000) study

18 stands, the relationship between these estimates and data from the sampled stands were

19 calculated.

The following four-step procedure was carried out to determine the

22 influence of stand-level differences in mountain pine beetle attack and emergence 
1 densities on estimates of stand-level net production of beetles, based on general mountain

2 pine beetle-lodgepole pine parameters obtained from the independent study.

1) Data from Shore et al. (2000) were used to obtain measures of the

5 relationships between diameter-at-breast-height (DBH) vs. percent tree mortality, and

6 DBH vs. net brood production (i.e., number of beetles that emerge from an individual tree

7 minus number of beetles that attacked that tree), respectively. The relationship between

$8 \mathrm{DBH}$ and percent tree mortality was obtained by calculating the proportion of lodgepole

9 pine killed for each diameter class (i.e., 0-5 cm, 5-10 cm, etc.). To determine the

10 relationship between DBH and tree-level net brood production, the following

11 relationships were calculated: (i) DBH vs. attack height, (ii) DBH vs. number of attacks

12 per $\mathrm{m}^{2}$ at $1.4 \mathrm{~m}$ above ground (attacks were multiplied by 1.6 to compensate for the

13 skewed sex ratio (Reid, 1963)), (iii) DBH vs. number of emerged beetles per $\mathrm{m}^{2}$ (the

14 number of emerged beetles was corrected as per Safranyik and Linton (1985) (see

15 equation 2 below) to compensate for the fact that more than one beetle will emerge per

16 hole at high attack densities). The total number of attacks and total number of emerged

17 beetles per tree were then estimated according to Safranyik (1988), taking the taper of the

18 trees and the lower attack densities higher up along the bole into account. Based on these

19 calculations, a formula was developed to estimate the net brood production for a tree with

20 a given $\mathrm{DBH}$, taking the $\mathrm{DBH}-$ related probability of attack into account.

2) Field data to calculate beetle productivity for individual stands were

23 obtained by intense sampling of 26 lodgepole pine stands, where a mountain pine beetle 
1 infestation had run its course or was close to the end. The stands were widely distributed

2 within British Columbia, Canada (Table 1). Within each stand, 8-11 variable radius plots

3 were established according to the following procedure. A transect line was laid out at a

4 random bearing, and plots were placed along the transect with random distances of

5 between $80-120 \mathrm{~m}$ separating them. If the boundary of the stand was reached, a new

6 transect was established at a random distance of between $80-120 \mathrm{~m}$, parallel to the

7 original transect. Within each plot, a prism (BAF 5) was used to select trees for sampling.

8 On each tree, at $1.4 \mathrm{~m}$ above ground, the number of attacks and the number of exit holes

9 were counted within $15 \times 30 \mathrm{~cm}$ rectangles, one on the north- and one on the south-facing

10 side of the tree. Ventilation holes and exit holes made by other insects can look very

11 similar to mountain pine beetle exit holes (Safranyik and Linton, 1985), so to make sure

12 that we only included mountain pine beetle exit holes, we also removed the bark and

13 examined the associated gallery systems.

14

3) Since trees were selected with prisms, we calculated a density factor for

16 each tree as follows (Husch et al., 2003):

$$
\mathrm{TDF}=\mathrm{BAF} \times\left(\mathrm{T}_{\mathrm{N}} /\left(\mathrm{BAFx}_{\mathrm{N}}\right)\right)
$$

Where: $\mathrm{TDF}=$ tree density factor (trees/ha), $\mathrm{BAF}=$ basal area factor, $\mathrm{T}_{\mathrm{N}}=$

21 number of trees sampled, and $\mathrm{P}_{\mathrm{N}}=$ number of plots sampled. 
1 The generalized net brood production of each stand, defined as the net brood production

2 based on the beetle-lodgepole pine parameters from the independent study (Shore et al.,

3 2000), was then calculated for each of the 26 stands as the sum of the net brood

4 production for each sampled tree, multiplied by the tree density factor for that tree.

4) The stand-specific net brood production per ha, defined as the net

7 production based on stand-specific beetle attack and emergence data from sampling, was

8 calculated as in "step 3" except that: (i) a stand-specific number of attacks per unit area,

9 multiplied by 1.6 to compensate for the skewed sex ratio normally found in mountain

10 pine beetle populations (Reid, 1963), was inserted in the formula described in "step 2"

11 instead of the value from the independent study, and (ii) a stand-specific regression line,

12 representing the relationship between DBH and number of exit holes per unit area

13 sampled in that stand, was used in the formula described in "step 2", instead of the

14 generalized regression line based on the independent dataset. We calculated a stand-

15 specific intercept of the line based on the mean DBH and the mean number of exit holes

16 per unit area for all trees within a stand. We assumed that the slope of this line is always

17 the same. Emergence was adjusted to compensate for the fact that, according to Safranyik

18 and Linton (1985), more than one beetle emerges from each exit hole at high attack

19 densities (equation 2).

$$
y=1.2635 x-0.3300
$$


Where: $\mathrm{y}=\log$ (number of emerged mountain pine beetles $\left./ 0.125 \mathrm{~m}^{2}\right), \mathrm{x}=$

$2 \log$ (number of holes in the bark $/ 0.125 \mathrm{~m}^{2}$ ).

A stand susceptibility index (SSI) was calculated for each of the 26 stands

5 sampled. We used a modification of the Shore and Safranyik (1992) system where some

6 discrete functions had been replaced with continuous functions according to Shore et al.

7 (2006).

9 To determine if the estimated net brood production can provide an

10 additional aid for stand prioritization, we calculated the correlation between stand

11 susceptibility index and stand net brood production. We should expect a correlation since

12 a stand's net brood production is related to the four variables that are used to calculate the

13 index, i.e., percentage of susceptible pine basal area, age, tree density and location

14 (latitude, longitude and elevation). If this correlation explains most of the variation, then

15 we would conclude that the estimated net brood production would not add to the index,

16 and hence would not be a useful tool for stand treatment prioritization.

The relationship between a stand's net brood production and its stand

19 susceptibility index is, to a large extent, determined by the relationships between DBH

20 vs. tree-level net brood production and DBH vs. basal area. Basal area, i.e., the area of

21 the cross-section of a tree trunk at breast height, is the metric used in the stand

22 susceptibility rating system to quantify tree mortality, and increases exponentially with

23 increasing DBH. The net production of beetles per tree also increases exponentially with 
1 increasing DBH. We generated curves of the rate of increase for these two relationships

2 to determine the tree diameters that contribute most, per tree, to any discrepancy between

3 net brood production and stand susceptibility rating. The estimated generalized net brood

4 production was calculated according to "step 1" described above.

Risk Rating Software (v.3), was used to calculate stand susceptibility index.

7 The rest of the data analyses were performed using SigmaPlot ${ }^{\circledR} 9.0$ (Systat Software Inc,

8 Point Richmond, CA, USA).

9 3. Results

11 independent study and represent the "general" mountain pine beetle-lodgepole pine

12 parameters: DBH $(\mathrm{cm})$ vs. proportion of lodgepole pine killed by mountain pine beetle

15 (Fig. 1):

16

$$
y=a /(1+\exp (-(x-x 0) / b)),
$$

$$
y=0.9395 x+130.4526 ; r^{2}=0.0063 ; P=0.2545
$$


2 (equation 4) the mean attack density was used instead (equation 5).

3

4

5

6

7

8

9

10

11

12

13

14

15

16

17

18

19

20

21

22

23

24

25

26

27

28

Mean attack density per $\mathrm{m}^{2}$ (adjusted for skewed sex ratio):

$$
y=153.7305
$$

DBH $(\mathrm{cm})$ vs. number of emerged beetles per $\mathrm{m}^{2}$ :

$$
y=36.8046 x-399.0261 ; r^{2}=0.0478 ; P=0.002
$$

$\mathrm{DBH}(\mathrm{cm})$ vs. attack height (m):

$$
y=0.3320 x-1.0589 ; r^{2}=0.3040 ; P=<0.0001
$$

(1)

The mean number of beetles attacking a tree with a certain $\mathrm{DBH}$, including the probability that the tree will be attacked, was calculated as follows (based on equation 3, 5, and 7 from the present study and equation 13 in Safranyik (1988), which states that $\mathrm{Ta}=129.2189\left(\mathrm{Xa}^{0.2964}\right)\left(\mathrm{D}^{1.7665}\right)\left(\mathrm{Hi}^{0.9430}\right) ; \mathrm{Ta}=$ Attack totals in individual trees; $\mathrm{Xa}=$ Attack density per square metre at $1.22 \mathrm{~m}$ on the bole; $\mathrm{D}=$ Tree diameter $(\mathrm{m})$ at $1.37 \mathrm{~m}$; $\mathrm{Hi}=$ Infested bole height $(\mathrm{m})$ ):

$$
\mathrm{y}=(3)(5)(7)(13 \text { in Safranyik 1988) }
$$

The mean number of beetles emerging from a tree of a given DBH, including the probability of attack on that tree, was calculated as follows (based on equations 3, 5, 6 and 7 above and equation 14 in Safranyik (1988), which states that $\mathrm{Tb}=$ $48.0586\left(\mathrm{Xb}^{0.6386}\right)\left(\mathrm{D}^{1.3264}\right)\left(\mathrm{Hi}^{0.7465}\right)$; Brood totals in individual trees; $\mathrm{Xb}=$ Brood density 
1 per square metre at $1.22 \mathrm{~m}$ on the bole; $\mathrm{D}=$ Tree diameter $(\mathrm{m})$ at $1.37 \mathrm{~m} ; \mathrm{Hi}=$ Infested

2 bole height $(\mathrm{m}))$ :

3

7 probability of attack for that tree, was calculated as follows (based on equations 8 and 9):

$$
y=(9)-(8)
$$

11 The stand-specific parameters from the twenty-six stands that were

12 intensively sampled in the present study are given in Table 1 . There was great variation in

13 mountain pine beetle productivity among stands, which was mainly due to large variation

14 in the number of beetles that emerge per unit area (Table 1, Intercept values for the stand-

15 specific version of the equation that were used to calculate the DBH related number of

16 emerged beetles per $\mathrm{m}^{2}$ ).

17

18 The relationship between estimates of net brood production per ha, based on

19 generalized vs. stand-specific mountain pine beetle-lodgepole pine parameters, is shown

20 in Fig. 2. This relationship can be described with the following equation:

$$
y=1.1897 x+12.8715 ; R^{2}=0.6236 ; P=<0.0001
$$


2 ratings and stand-specific net brood production estimates (Fig. 3, equation 12).

$$
\mathrm{y}=0.3471 \mathrm{x}+24.5882 ; \mathrm{R}^{2}=0.1371 ; \mathrm{P}=0.0626
$$

7 and plotted in Fig. 4. For comparative purposes, the relationship between the DBH of a

8 lodgepole pine and its net brood production (described in equation 10) is also plotted in

$9 \quad$ Fig. 4.

$$
\mathrm{y}=\pi(x / 2)^{2}
$$

\section{4. Discussion}

14 beetle net brood production based on stand parameters and known tree-insect

15 interactions. We assumed that in addition to potential stand volume losses, treatment

16 priority should also take into account the potential contribution by a stand to the next

17 generation of beetles. In other words, we assumed that there is a direct relationship

18 between the number of brood beetles contributed by a stand to the next generation, and

19 the impact on outbreak progression by treatment activities such as harvesting. Thus, when

20 assigning harvesting priority among stands with similar susceptibility scores, those with

21 the highest estimated net production of beetles should be given preference. 
As expected, there was great variation in beetle productivity among similar

2 sized trees in different stands. This variation may be due to variation among stands with

3 regard to climatic suitability, host defenses, etc. (Safranyik and Carroll, 2006). However,

4 this variation had only a minor influence compared to that of the tree diameter

5 distribution on a stand's net production of brood beetles. Thus, before any beetle attack

6 occurs, calculations can be made, based solely on tree diameter distributions and

7 generalized parameters, which explain a large part of the variation in expected stand level

8 net brood production (Fig. 2).

There were two reasons why larger trees generally produced more beetles

11 than the small trees: (i) the relationship between tree diameter and percent beetle-caused

12 tree mortality tended to follow a sigmoid distribution with larger trees being attacked

13 more frequently (Fig. 1); and (ii) among attacked trees the larger ones generally had a

14 higher net production of beetles. The higher net production was due to larger trees having

15 a higher maximum height of attack, i.e., they were attacked over a much larger surface

16 area than smaller diameter trees, they produced more beetles per $\mathrm{m}^{2}$ of bark at DBH, and

17 other general factors that are summarized in Safranyik (1988).

There was no significant correlation between the diameter of the attacked

20 trees and beetle attack density and there was only a weak correlation between the

21 diameter of attacked trees and the number of emerged beetles per $\mathrm{m}^{2}$. Tree diameter may

22 be a significant variable when individual stands are analyzed separately (Reid, 1963, Cole

23 and Amman, 1969) but when data from several separate locations are incorporated into a 
1 single regression the strength of such correlations tend to be noticeably weaker

2 (Berryman, 1976). The average attack density was relatively high, but not extreme (see

3 Berryman et al. (1985) for a literature review). This suggests that the vigor of the

4 sampled trees was relatively high (Raffa and Berryman, 1983).

Estimates of net brood production can provide an additional aid for stand

7 prioritization since the stand susceptibility index explains little of the variation in net

8 brood production (Fig. 3). The largest trees contributed most, per tree, to the discrepancy

9 between net brood production and stand susceptibility rating (Fig. 4). For example, a 35

$10 \mathrm{~cm}$ DBH tree have a basal area that is approximately twice as large as a $25 \mathrm{~cm}$ DBH tree

11 whereas the net production of beetles is more than three times as high in a $35 \mathrm{~cm} \mathrm{DBH}$

12 tree compared to a $25 \mathrm{~cm} \mathrm{DBH}$ tree. Thus, the higher the proportion of a stand that is

13 made up of large trees the larger the discrepancy between net brood production and stand

14 susceptibility.

The estimates of the net brood production should be treated with some

17 caution since they are based on a limited number of parameters and, most likely,

18 simplified relationships. It is, for example, likely that the calculated net production in

19 small trees is slightly overestimated since we used a linear regression to represent the

20 relationship between DBH and number of emerged beetles per $\mathrm{m}^{2}$. In reality the net

21 production probably drops sharply when the phloem is too thin for the beetle to survive.

22 This has, however, only a minor influence on the stand-level net production estimate. 
The precision of the net brood production estimates based on generalized

2 parameters can probably be improved if the larger dataset, which we used to evaluate the

3 model in the present study, was used to calculate the mountain pine beetle-lodgepole pine

4 parameters, i.e., DBH vs. brood production per $\mathrm{m}^{2}$, etc. We also used the Shore and

5 Safranyik (1992) location factor in the calculation of the stand susceptibility index.

6 Björklund and Lindgren (submitted manuscript) showed by meta analysis that the

7 location factor explained 53\% of the variation of stand-level mortality of lodgepole pine

8 during mountain pine beetle outbreaks. Changing climatic conditions have led to the

9 development of a more sensitive climatic suitability index (Carroll et al., 2004), so it is

10 possible that further improvement might be accomplished if this index is incorporated in

11 the model (Cudmore, in prep.).

To our knowledge, this is the first time that stand parameters have been

14 used to predict insect population parameters for the explicit purpose of forest

15 management. The approach used in this study, i.e., to evaluate the precision of net beetle

16 production estimates made before the host is attacked, may be useful also in other

17 systems with aggressive bark beetle species where managers need to rank areas in order

18 of priority with regard to treatments.

\section{Acknowledgements}

This project was funded by the Government of Canada through the

21 Mountain Pine Beetle Initiative and administered by Natural Resources Canada,

22 Canadian Forest Service. Publication does not necessarily signify that the contents of this

23 report reflect the views or policies of Natural Resources Canada - Canadian Forest 
1 Service. Mention in this publication of any commercial product or service does not

2 constitute endorsement of such by the Canadian Forest Service or the Government of

3 Canada. Les Safranyik and one anonymous referee are acknowledged for comments on

4 an earlier version of the manuscript. We thank Simon Goring, Marnie Graf, Erin Carlson,

5 Mirco Muntener, Crystal Braun, Khya Saban, and Jeff Selesnic for assistance in the field,

6 and employees of the BC Ministry of Forests and Range for help with locating field sites.

\section{References}

8 Amman, G.D., Cole, W.E. 1983. Mountain pine beetle dynamics in lodgepole pine forests. Part II: population dynamics. USDA Forest Service, Intermountain Forest and Range Experiment Station, General Technical Report INT-145. 59 p.

12 Berryman, A. A. 1976. Theoretical explanation of mountain pine beetle dynamics in lodgepole pine forests. Environmental Entomology 5, 1225-1233.

15 Carroll, A.L., Taylor, S.W., Régnière, J., Safranyik, L. 2004. Effects of climate change 16 on range expansion by the mountain pine beetle in British Columbia. In: Shore,

17 T.L., Brooks, Stone, J.E. (Eds.), Challenges and Solutions: Proceedings of the

18 Mountain Pine Beetle Symposium. Kelowna, British Columbia. October 30-31,

19 2003. Natural Resources Canada, Canadian Forest Service, Pacific Forestry

20 Centre, Victoria, British Columbia, Information Report BC-X-399. pp. 223-232. 
1 Cole, W.E., Amman, G.D. 1969. Mountain pine beetle infestations in relation to

2 lodgepole pine diameters. Research Note INT-95. Forest Service, Intermountain

3 Forest and Range Experiment Station, Ogden, UT, pp. 1-7.

4

5 Husch, B., Beers, T.W., Kershaw, Jr., J.A. 2003. Forest mensuration, 4th ed. J. Wiley, $6 \quad$ New York.

8 Raffa, K. F., Berryman, A. A. 1983. The role of host plant resistence in the colonization 9 behavior and ecology of bark beetles (Coleoptera, Scolytidae). Ecological $10 \quad$ Monographs 53, 27-49.

12 Reid, R. W. 1963. Biology of the mountain pine beetle, Dendroctonus monticolae Hopkins, in the east Kootenay region of British Columbia. III. Interactions between the beetle and its host, with emphasis on brood mortality and survival. Canadian Entomologist 95, 225-238.

17 Risk Rating Software (v.3). Available from: http://www.pfc.forestry.ca/entomology/mpb/tools/DSS/software_e.html

20 Safranyik, L. 1968. Development of a technique for sampling mountain pine beetles in lodgepole pine. Ph.D. thesis, University of British Columbia, Vancouver, BC. pp. $1-195$. 
1 Safranyik, L. 1988. Estimating attack and brood totals and densities of the mountain pine

9 Safranyik, L., Carroll, A.L. 2006. The biology and epidemiology of the mountain pine beetle in individual lodgepole pine trees. The Canadian Entomologist 120, 323331.

Safranyik, L., Linton, D.A. 1985. The relationship between density of emerged Dendroctonus ponderosae (Coleoptera: Scolytidae) and density of exit holes in lodgepole pine. The Canadian Entomologist 117, 267-275.

beetle in lodgepole pine forests. In: Safranyik, L., Wilson, W.R. (Eds.), The mountain pine beetle: a synthesis of biology, management, and impacts on lodgepole pine. Natural Resources Canada, Canadian Forest Service, Pacific Forestry Centre, Victoria, British Columbia, pp. 3-66.

Safranyik, L., Shrimpton, D.M., Whitney, H.S. 1975. An interpretation of the interaction between lodgepole pine, the mountain pine beetle and its associated blue stain fungi in western Canada. In: Baumgartner, D.M. (Ed.), Management of lodgepole pine ecosystems. Washington State University Cooperative Extension Service, Pullman, WA, pp. 406-428.

Shore, T. L., Safranyik, L. 1992. Susceptibility and risk rating systems for the mountain pine beetle in lodgepole pine stands. Forestry Canada, Pacific Forestry Centre, Victoria, BC. Information Report BC-X-336, pp. 1-12. 
2 Shore, T. L., Safranyik, L., Lemieux, J. P. 2000. Susceptibility of lodgepole pine stands to the mountain pine beetle: testing of a rating system. Canadian Journal of Forest

$4 \quad$ Research 30, 44-49.

6 Shore, T.L., Riel, W.G., Safranyik, L., Fall, A. 2006. Decision Support Systems. In:

7 Safranyik, L., Wilson, B. (Eds.) The mountain pine beetle: A synthesis of biology,

8 management and impacts on lodgepole pine. Natural Resources Canada, Canadian

9 Forest Service, Pacific Forestry Center, Victoria, BC, Canada. pp. 193-229. 


\section{Tables}

2 Table 1. Parameters related to the net production of Dendroctonus ponderosae and stand characteristics of the studied lodgepole pine 3 forests in British Columbia, Canada.

\begin{tabular}{|c|c|c|c|c|c|c|c|c|c|c|}
\hline Forest district & Latitude $(\mathrm{N})$ & Longitude (W) & Elevation & \# Plots & \# Pines $^{1}$ & $\%$ Pine & Age & DBH of pine & Attack density $^{2}$ & Intercept $^{3}$ \\
\hline Prince George & 53.6 & 123.0 & 855 & 10 & 84 & 79 & 120 & 24 & 126 & 493 \\
\hline Prince George & 53.4 & 123.0 & 872 & 10 & 68 & 82 & 103 & 23 & 105 & 642 \\
\hline Prince George & 53.4 & 123.7 & 783 & 11 & 86 & 88 & 147 & 18 & 110 & 457 \\
\hline Prince George & 54.4 & 122.6 & 764 & 10 & 71 & 86 & 115 & 20 & 135 & 383 \\
\hline Prince George & 54.2 & 122.8 & 751 & 10 & 83 & 76 & 82 & 23 & 104 & 164 \\
\hline Prince George & 53.7 & 123.4 & 950 & 11 & 110 & 75 & 124 & 17 & 84 & 457 \\
\hline Prince George & 53.7 & 123.4 & 850 & 11 & 60 & 79 & 151 & 20 & 86 & -38 \\
\hline Prince George & 53.8 & 123.5 & 883 & 10 & 111 & 97 & 89 & 16 & 91 & 871 \\
\hline Prince George & 53.5 & 123.3 & 765 & 10 & 67 & 68 & 116 & 20 & 161 & 165 \\
\hline Prince George & 53.4 & 123.7 & 898 & 10 & 78 & 82 & 137 & 16 & 82 & 708 \\
\hline Vanderhoof & 53.6 & 124.9 & 850 & 10 & 75 & 95 & 58 & 15 & 145 & 476 \\
\hline Vanderhoof & 53.9 & 124.4 & 1013 & 10 & 80 & 90 & 89 & 17 & 105 & 539 \\
\hline Vanderhoof & 53.9 & 124.4 & 805 & 10 & 90 & 99 & 65 & 16 & 108 & 131 \\
\hline Vanderhoof & 53.9 & 124.4 & 832 & 10 & 92 & 86 & 61 & 16 & 722 & 666 \\
\hline Vanderhoof & 53.8 & 124.3 & 735 & 10 & 102 & 84 & 93 & 19 & 147 & 351 \\
\hline 100 Mile House & 51.6 & 121.4 & 1147 & 10 & 41 & 64 & 62 & 14 & 132 & 959 \\
\hline 100 Mile House & 52.0 & 121.3 & 956 & 10 & 95 & 99 & 120 & 27 & 73 & 733 \\
\hline 100 Mile House & 52.0 & 121.2 & 1003 & 10 & 123 & 94 & 122 & 23 & 789 & 545 \\
\hline Columbia & 51.1 & 116.5 & 1302 & 10 & 43 & 39 & 124 & 30 & 136 & 127 \\
\hline Columbia & 51.2 & 116.6 & 1120 & 10 & 57 & 67 & 119 & 26 & 160 & -78 \\
\hline Columbia & 51.2 & 116.6 & 1140 & 10 & 75 & 93 & 84 & 20 & 188 & 388 \\
\hline Rocky Mountain & 49.6 & 116.2 & 1500 & 8 & 61 & 91 & 111 & 19 & 148 & 482 \\
\hline Rocky Mountain & 49.6 & 116.2 & 1756 & 10 & 101 & 92 & 107 & 12 & 88 & 499 \\
\hline Rocky Mountain & 49.6 & 116.2 & 1473 & 10 & 99 & 99 & 110 & 15 & 163 & 233 \\
\hline Rocky Mountain & 49.6 & 116.2 & 1707 & 10 & 49 & 74 & 105 & 19 & 131 & 746 \\
\hline Rocky Mountain & 49.6 & 116.2 & 1296 & 10 & 50 & 57 & 94 & 14 & 152 & 226 \\
\hline
\end{tabular}

$5 \quad 1=$ Number of pines that were sampled.

$6 \quad 2=$ Mean number of attacks per $\mathrm{m}^{2}$ (adjusted for skewed sex ratio) at $1.4 \mathrm{~m}$ above ground.

$7 \quad{ }^{3}=$ Intercept value for the stand-specific version of equation 6 which was used to calculate the DBH related number of emerged beetles per $\mathrm{m}^{2}(\mathrm{see}$ Material and 8 methods). 


\section{Figure captions}

2 Fig. 1. Relationship between the $\mathrm{DBH}$ of a lodgepole pine tree and its probability of

3 being killed by mountain pine beetles (MPB), Dendroctonus ponderosae. The

4 relationship could be characterized by a three-parameter sigmoid equation.

6 Fig. 2. Relationship between estimates of net brood production based on generalized

7 Dendroctonus ponderosae-Pinus contorta parameters vs. stand-specific parameters, i.e.

8 attack and emergence data from Shore et al. (2000) vs. from that specific stand. Each dot

9 represents one stand.

11 Fig. 3. Relationship between stand susceptibility index and estimates of net brood

12 production based on stand-specific Dendroctonus ponderosae-Pinus contorta parameters.

13 N.B.: The aim of the stand susceptibility index is not to predict net brood production.

15 Fig. 4. Relationship between a tree's DBH and its estimated net brood production based

16 on generalized Dendroctonus ponderosae-Pinus contorta parameters (including the

17 probability of beetle caused mortality (see text)). To make a comparison to measures that

18 are based on basal area possible the DBH vs. basal area relationship were also plotted. 


\section{Figures}

3 Fig. 1.

4

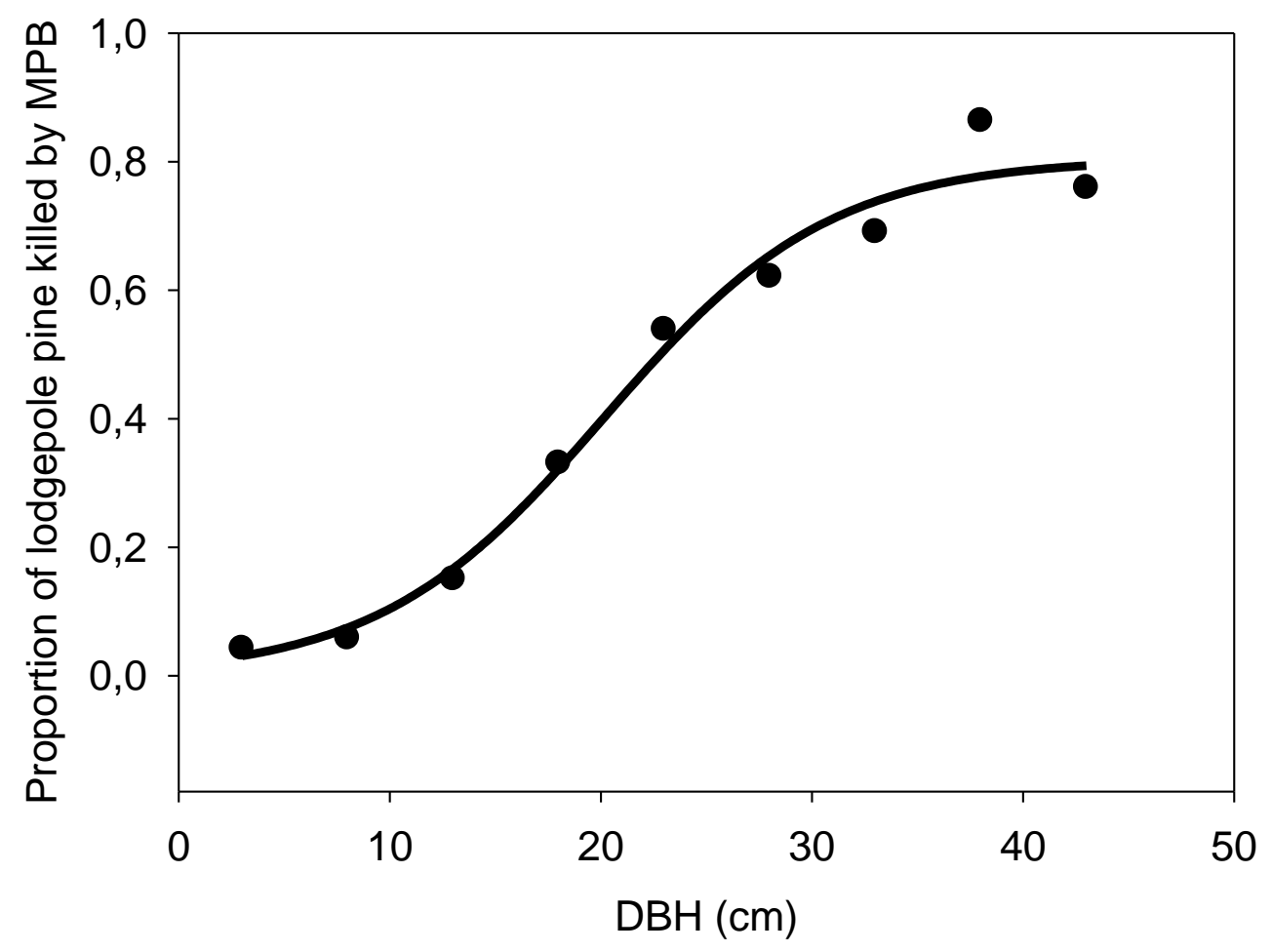

5

6 
1 Fig. 2.

2

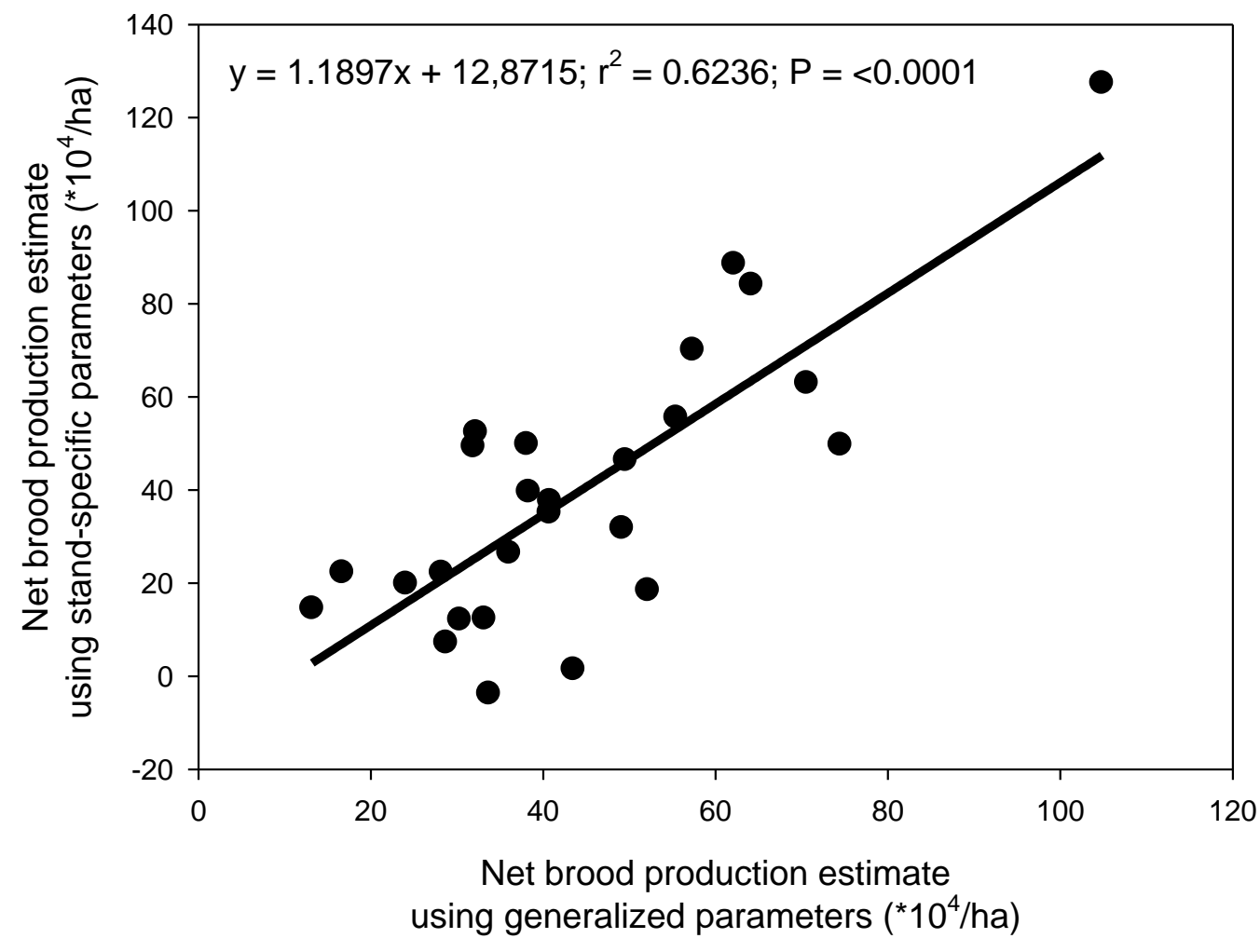

3

4

5 
1 Fig. 3.

2

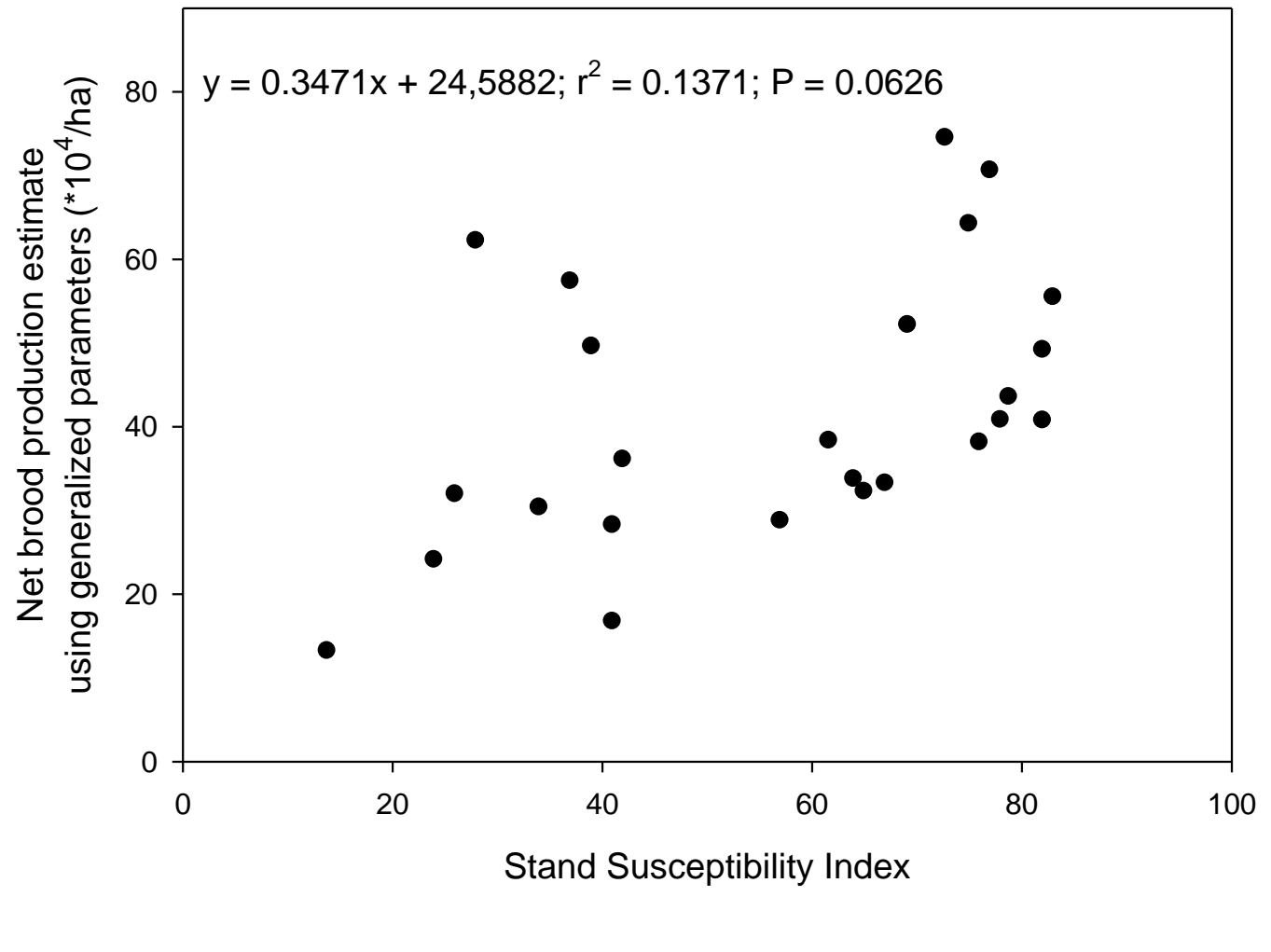


1 Fig. 4.

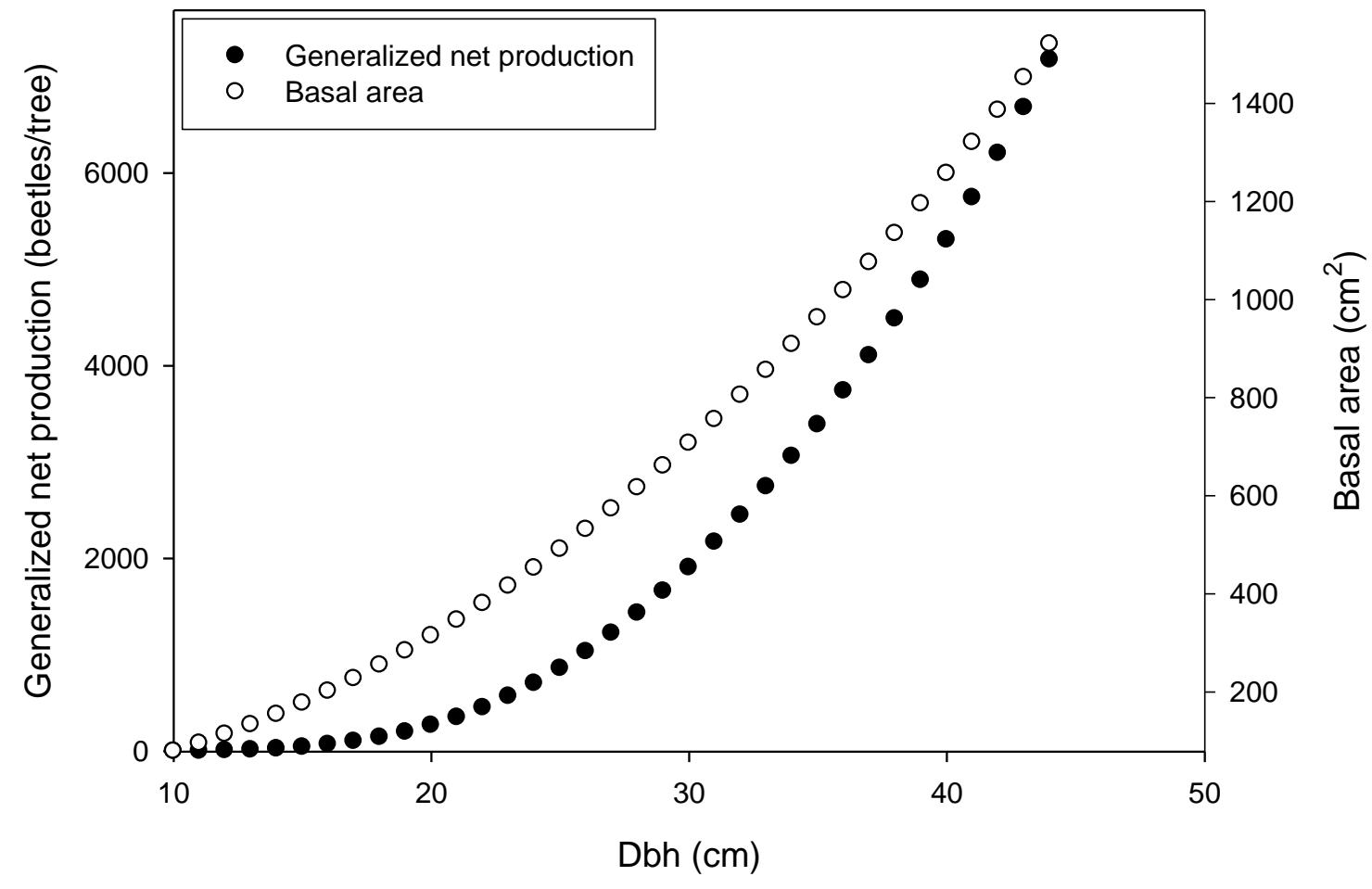

